REVIEW SERIES

\title{
Sleep - 7: Positive airway pressure therapy for obstructive sleep apnoea/hypopnoea syndrome
}

\author{
P Gordon, M H Sanders
}

The use of continuous positive airway pressure (CPAP) in treating symptoms associated with OSAHS is reviewed. Although it is an imperfect intervention, it continues to evolve and improve in such a way that patients who would not have been able to use this treatment even in the recent past can benefit from it today.

See end of article for authors' affiliations

Correspondence to: DrM H Sanders, Division of Pulmonary, Allergy and Critical Care Medicine, University of Pittsburgh School of Medicine, Montefiore University Hospital, North-1292, Pittsburgh, PA 15213, USA; sandersmh@msx. upmc.edu

Received 19 March 2003 Accepted

23 September 2004
O bstructive sleep apnoea/hypopnoea (OSAHS) is a common disorder which is characterised by instability of the upper airway during sleep resulting in reduction or elimination of airflow, oxyhaemoglobin desaturation, and sleep disruption. The prevalence of OSAHS has been estimated at $24 \%$ in men and $9 \%$ in women. ${ }^{1}$ There is increasing evidence to support OSAHS as a risk factor for cardiovascular and cerebrovascular disorders including hypertension, congestive heart failure, myocardial infarction, and stroke. ${ }^{2-5}$ In addition, OSAHS is associated with impaired neurocognitive function and alertness believed to contribute to the increased rates of motor vehicle crashes and traffic fatalities. ${ }^{6-9}$ Thus, in view of the considerable exposure within the general population to OSAHS and its notable consequences, expeditious diagnosis and effective treatment of these patients has important individual as well as public health benefits.

The mainstay of medical treatment of OSAHS is administration of non-invasive positive airway pressure (PAP) during sleep. In this review we treatment for OSAHS, focusing on current hypotheses regarding possible mechanisms of action, evidence for its impact on OSAHS associated morbidities, and data describing populations which may or may not benefit from PAP.

\section{MECHANISM(S) BY WHICH PAP STABILISES THE UPPER AIRWAY DURING SLEEP}

Although continuous positive airway pressure (CPAP) has been used to treat patients with OSAHS for over two decades, our understanding regarding the mechanism of action continues to evolve. The most widely accepted view is that the positive pressure provides a mechanical stent of the upper airway (fig 1). This theory was first suggested by Sullivan et al in $1981^{10}$ and was subsequently supported by Alex et $a l^{11}$ who compared the relationship between oesophageal pressure swings and inspiratory airflow during will summarise the available data on PAP
Thorax 2005;60:68-75. doi: 10.1136/thx.2003.007195

breathing without and with CPAP in normal awake subjects. These investigators observed that, at a given oesophageal pressure, inspiratory airflow was greater during CPAP administration despite the presence of decreased genioglossus muscle activation compared with baseline.

Some investigators have suggested that increases in lung volume during PAP administration mediate the upper airway stabilising effect of this treatment. This concept is based on data indicating that patients with OSAHS have greater lung volume dependency of pharyngeal cross sectional area than individuals without OSAHS..$^{12}$ In other words, pharyngeal cross sectional area, measured during wakefulness by the technique of acoustic reflection, decreases to a greater extent in patients with OSAHS than in normal individuals as lung volume decreases. ${ }^{12}{ }^{14}$ Two mechanistic theories have been proposed to explain this modulation. One suggests that PAP associated augmentation of lung volume elicits a reflex which increases upper airway dilator muscle tone. The other theory proposes that forces associated with increased lung volume are transmitted to the upper airway via the trachea (fig 2). The resulting stretch or "tracheal tug" stiffens and stabilises the upper airway. ${ }^{15}{ }^{16}$ The feasibility of tracheal tug as a mediator of upper airway resistance has been supported by experiments using animal models. ${ }^{17-20}$

Regardless of the proposed mechanisms through which changes in lung volume may modulate upper airway stability, the evidence regarding the operational significance of this pathway is, at best, contradictory. Support for reflex augmentation of upper airway dilator muscle activity is diminished in separate reports by Strohl et al $^{21}$ and Rapoport et a $l^{22}$ who indicated that genioglossus muscle EMG activity is either reduced or variable during CPAP use which eliminates obstructive events.

Although Sériès et al suggested that augmentation of end expiratory lung volume by application of negative end expiratory pressure using an "iron lung" reduced the frequency of apnoea during sleep, ${ }^{23}$ other investigators using the same technique failed to observe a favourable effect. ${ }^{24}$ In addition, a separate study by Sériès et al ${ }^{14}$ showed that upper airway resistance progressively decreases during administration of

Abbreviations: $\mathrm{AHI}$, apnoea hypopnoea index; $\mathrm{CHF}$, congestive heart failure; CPAP, continuous positive airway pressure; CSB, Cheyne-Stokes breathing; OSAHS obstructive sleep apnoea/hypopnoea syndrome; PAP, positive airway pressure 


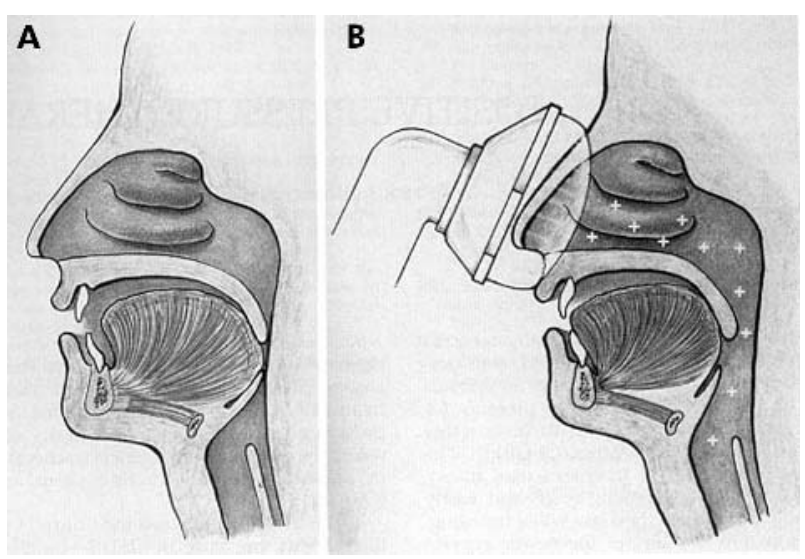

Figure 1 Mechanism by which positive pressure stents open the upper airway. Note the closure of the oropharynx by the soft palate, reducing air leak through the mouth. Reprinted with permission from the slide set of the American Academy of Sleep Medicine.

increasing levels of CPAP even when lung volume is maintained by application of positive extrathoracic pressure. Thus, it appears that the primary mechanism for improvement in upper airway stabilisation by PAP administration is related to a mechanical splinting effect.

\section{OUTCOMES OF TREATMENT WITH PAP}

Optimising patient acceptance and adherence to PAP treatment remains a major clinical challenge. Significant work has been done to determine which patients with OSAHS will adhere to a PAP prescription and who will derive physiological and quality of life benefits from this treatment. It has been recommended that all symptomatic patients with OSAHS (who by definition have an apnoea hypopnoea index, AHI, of >5) should receive treatment. ${ }^{25}$ The Amercian Academy of Sleep Medicine (formerly the American Sleep Disorders Association) guidelines for CPAP therapy recommend its use for patients with an apnoea index (mean number of apnoeas per hour of sleep) of $\geqslant 20$ and for symptomatic patients with an AHI (mean number of apneas+hypopneas per hour of sleep) or respiratory arousal index (mean number of arousals per hour of sleep) of $\geqslant 10 .^{26}$ In the United States Medicare will cover CPAP devices for patients with an AHI of $\geqslant 15$, or patients with sequelae of OSAHS and an AHI of 5-14. Such sequelae include excessive daytime sleepiness, impaired cognition, hypertension, coronary artery disease, cerebrovascular accident, mood disorders, and insomnia. ${ }^{27}$

\section{Sleepiness and alertness}

When compared with sham CPAP, it has not been proved that asymptomatic patients with severe OSAHS have improved daytime function or decreased sleepiness after 6 weeks of CPAP. ${ }^{28}$ On the other hand, symptomatic patients with mild OSAHS (AHI 5-15) as well as severe OSAHS have been shown to experience a reduction in subjective as well as objective measures of daytime sleepiness with CPAP treatment. ${ }^{29-36}$ Several studies, including those employing subtherapeutic levels of CPAP as a control, have demonstrated observed improved quality of life in symptomatic patients with even mild OSA HS. ${ }^{37-40}$

Additional support for the salutary impact of CPAP on daytime sleepiness, as well as demonstrating the importance of patient adherence to treatment, was provided by Kribbs et $a l^{41}$ who reported that daytime sleepiness (measured by the Epworth Sleepiness Scale and Maintenance of Wakefulness Test) improved significantly after prolonged therapeutic
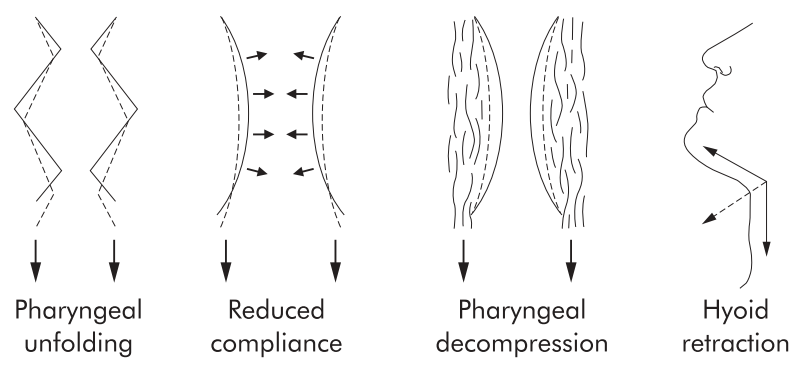

Figure 2 Possible mechanisms by which "tracheal tug" influences upper airway patency. Reprinted with permission from Van de Graaff. ${ }^{17}$

CPAP. However, just one night without treatment was sufficient to reverse these improvements, despite a reduced AHI compared with pretreatment levels (mean AHI of 37 during one night off CPAP following chronic treatment $v$ pretreatment AHI of 56).

\section{Neurocognition and performance}

OSAHS adversely affects certain neurocognitive functions including memory and learning, as well as task performance such as driving. ${ }^{42-44}$ Studies have found improved cognitive performance after adequate CPAP treatment. Montserrat et al reported that, compared with placebo, CPAP was associated with significantly improved daytime function as measured by the Functional Outcomes Sleep Questionnaire (FOSQ). ${ }^{40}$ Engleman observed that even an average CPAP use of 3.4 hours per night was associated with improved cognitive task performance and attention. ${ }^{30}$

Motor vehicle crashes represent another major morbidity and mortality attributable to OSAHS. ${ }^{6-9}$ Engleman and coworkers noted that patients with higher levels of adherence to treatment with CPAP reported fewer traffic accidents relative to the pretreatment period. ${ }^{45}$ Additional studies have confirmed the beneficial effects of therapeutic CPAP on driving performance and motor vehicle crashes. ${ }^{46}{ }^{47}$

In summary, CPAP use has clearly been shown to have a favourable impact on daytime sleepiness in sleepy patients with OSAHS, driving performance as measured by driving simulators, and also accident rates. In addition, even 3-4 hours per night of CPAP use can improve measures of cognition and daytime vigilance.

\section{Cardiovascular outcomes}

There is growing recognition that OSAHS is associated with a notably increased risk for adverse cardiovascular and cerebrovascular consequences. ${ }^{2}{ }^{5} 48$ The risk for hypertension engendered by OSAHS is increasingly acknowledged ${ }^{28-52}$ but the impact of PAP on hypertension remains controversial. Dimsdale et al reported a decrease in nocturnal blood pressure but no decrease in diurnal hypertension with CPAP use in patients with OSAHS and hypertension. ${ }^{53}$ However, several other studies have found that CPAP therapy reduces diurnal and nocturnal blood pressure in hypertensive patients with OSAHS. ${ }^{54-58}$ Although small, this reduction in blood pressure may have meaningful health benefits. ${ }^{59}$

Congestive heart failure (CHF) may be associated with sleep disordered breathing, including OSAH, central sleep apnoea, and Cheyne-Stokes breathing (CSB). ${ }^{60}$ Left ventricular failure, which can be worsened by the exaggerated intrathoracic pressure swings during apnoeas and hypopnoeas, ${ }^{61}$ is improved by use of nasal CPAP ${ }^{62-69}$ Furthermore, recent data suggest that CPAP administration to patients with CHF reduces morbidity with improved New York Heart Association functional class and has a favourable impact on mortality in patients with CSB. ${ }^{67}$ Malone et al reported improved left ventricular ejection fraction (LVEF) in CHF 
patients with OSAHS after CPAP and a reduction in LVEF during temporary withdrawal of CPAP. ${ }^{61}$ Krieger et al reported that CPAP normalised LVEF as well atrial natriuretic peptide (ANP) in patients with mild CHF and sleep apnoea. ${ }^{70}{ }^{71} \mathrm{CSB}$ is an independent predictor of mortality from CHF. CPAP has been shown to eliminate CSB and decrease mortality in patients with this pattern of periodic breathing. ${ }^{67}$ There is some question as to whether CPAP confers any added benefit in reducing CHF morbidity beyond oxygen therapy alone, although this question continues to be an area of active investigation. $^{72}$

The mechanism by which CPAP improves cardiovascular outcomes is unknown, although there is increasing evidence that a reduction in sympathetic tone may play an important role. Adverse cardiac consequences in patients with OSAHS may be attributable to the increaseded sympathetic autonomic activity that has been noted in these patients during wakefulness as well as sleep. ${ }^{73-76}$ Hypoxia, and potentially hypercapnia, resulting from apnoeas and hypopnoeas may account for this increased sympathetic activity during sleep, although the mechanism for increased diurnal autonomic activity is less clear. Importantly, prolonged CPAP therapy significantly reduces diurnal sympathetic tone in patients with OSAHS (fig 3).68 747778 It has been speculated that the reduction in sympathetic activity in patients with OSAHS associated with CPAP use may have a favourable effect on cardiovascular outcomes in much the same way as beta blockade, although this has not been shown to date. Further investigation is warranted to clarify these findings.

Dean $e t a l^{79}$ found evidence of increased atherogenesis in OSAHS. Since this study there has been significant work regarding the relationship between OSAHS and vascular endothelial cell function, as well as the potential modifying role of CPAP therapy in this regard. ${ }^{80} 81$ OSAHS has been associated with increased levels of soluble cell adhesion molecules which are correlated with atherosclerosis. It may therefore be significant that CPAP therapy reduces levels of E-selectin and soluble intercellular adhesion molecule-1, with persistence of this effect through 6 months of treatment. ${ }^{80}$

Duchna et $a l^{81}$ reported evidence of impaired endothelial cell function in patients with OSAHS with impaired vasodilation in response to bradykinin and nitroglycerin. This dysfunction could contribute to the increased cardiovascular and cerebrovascular morbidity associated with OSAHS. It is noteworthy therefore that the vasodilatory responsiveness to bradykinin increased significantly and there was a trend towards increased vasodilation in response to nitroglycerin following 60 days of CPAP treatment.

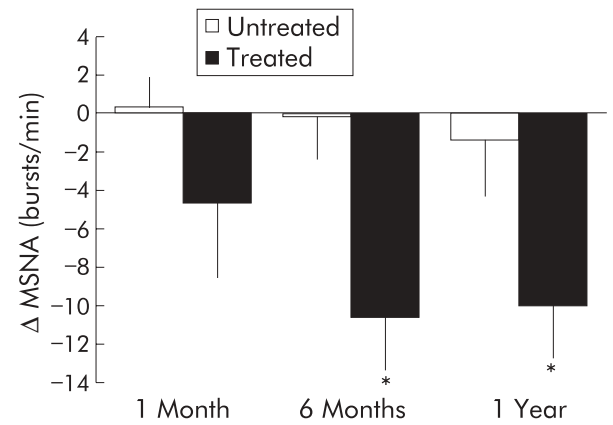

Figure 3 Change in muscle sympathetic nerve activity (MSNA) in untreated patients with sleep apnoea $(n=9)$ and in patients treated with CPAP at 1 month, 6 months, and 1 year $(n=11)$. Sympathetic activity decreased significantly in the treated patients but not in the untreated patients. Reprinted with permission from Narkiewicz et al. ${ }^{77}$
Leptin levels are raised in patients with OSAHS. ${ }^{82}$ This may be significant in that leptin modulates the degree and distribution of fat deposition with increased visceral fat having an association with coronary heart disease. Furthermore, leptin may be associated with increased sympathetic activation ${ }^{83} 84$ with a consequent adverse cardiovascular impact. In this context, it may be noteworthy that CPAP has been shown to reduce serum leptin levels and decrease the proportion of visceral fat in OSAHS patients even when overall weight is unchanged. ${ }^{85}$

Taken together, the evidence listed above provides strong evidence that CPAP favourably modifies multiple factors at the neurophysiological and molecular levels which promote cardiovascular disease.

\section{ACCEPTANCE OF AND ADHERENCE TO CPAP}

Acceptance refers to the patient's perception of CPAP and willingness to consider its use. Acceptance is a necessary first step to adherence but should be considered separately. Estimated rates of acceptance range from $72 \%$ to $91 \%{ }^{86-91}$ Estimates of adherence to CPAP therapy vary, but overall adherence is suboptimal. Kribbs and colleagues found that when adherence was defined as use for at least 4 hours on at least $70 \%$ of nights, only $46 \%$ of patients qualified. $^{92}$ Subsequently, Engleman et al reported a mean daily CPAP use of 4.7 hours. ${ }^{93}$ Not only may the mean number of hours of CPAP use vary across patients, but so may the pattern of use. Weaver et al reported that adherence followed a bimodal distribution in which half of patients used CPAP at least $90 \%$ of nights with a mean of 6.22 hours of nightly use while the other half used CPAP intermittently and nightly use varied greatly. ${ }^{94}$ Attempts have been made to identify factors associated with higher rates of use, as the degree of adherence positively correlates with patient outcomes. ${ }^{38} 45$ In evaluating 1200 patients with OSAHS, McArdle and coworkers found that independent predictors of self-reported 5 year adherence to CPAP included presence of snoring, magnitude of AHI, and degree of sleepiness. ${ }^{95}$ Engleman found that, in patients with mild OSAHS, those who were more adherent to treatment had higher AHIs than those who used CPAP less regularly. ${ }^{96}$ On the other hand, other studies have found no association between AHI and adherence to treatment. $^{3790939798}$ The incidence of adverse effects was inversely correlated with CPAP use in one study. ${ }^{45}$

From a clinical management perspective, it is important to note the observation that intermittent CPAP use within the first few weeks following initiation of treatment is associated with shorter nightly use, ${ }^{94}$ because it suggests that clinicians have a brief window of opportunity to address potential impediments to adherence before patients establish an unacceptable pattern of use. Suboptimal adherence to CPAP therapy notwithstanding, it is important for clinicians to appreciate that the rates of adherence are comparable with other treatments such as metered dose inhalers (MDI) in asthma for which adherence has been reported as $37-52 \%$ when objectively measured. ${ }^{99}{ }^{100}$ Thus, although adherence to CPAP remains suboptimal, it is similar to or better than that of less intrusive treatments for other disorders.

Suboptimal adherence has been a motivator for the development of PAP modalities as alternatives to conventional CPAP which will be discussed later in this article. Other strategies have included intensifying follow up of patients with OSAHS on PAP therapy. In a prospective randomised trial, Hoy et a ${ }^{101}$ implemented a programme of intensive education and adaptation, including three nights of CPAP trials in the sleep facility and subsequent rigorous follow up. The patients randomised to intensive support were significantly more adherent to treatment at 1,3 , and 6 months than were the patients randomised to usual care 


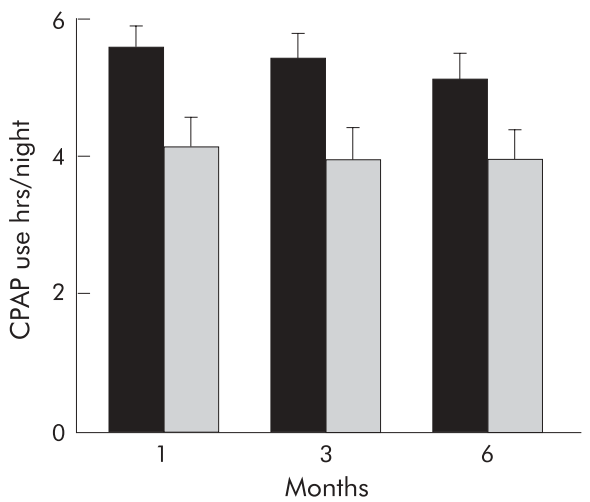

Figure 4 Nightly adherence to CPAP at 1, 3, and 6 months in sleep apnoea patients with intensive (filled bars) versus standard (shaded bars) support. The difference between groups is significant $(p=0.003)$. Reprinted with permission from Hoy et al. ${ }^{101}$

(fig 4). ${ }^{101}$ In contrast, employing a similar study design, Hui et $a l^{102}$ found no difference in CPAP use between groups randomised to usual care or "augmented support".

\section{SIDE EFFECTS/ADVERSE EFFECTS}

Engleman reported that the incidence of side effects directly affected patient adherence to treatment, ${ }^{93}$ although other studies have not found such a correlation. ${ }^{98} 103$

Regardless of the nature of the relationship between side effects and adherence, it seems prudent to minimise any adverse impacts associated with PAP therapy. In general, these can be categorised as those related to nasopharyngeal symptoms, those related to the interface or nasal route of delivery, and those specifically related to the magnitude of pressure.

The most often reported nasopharyngeal symptoms include increased congestion and rhinorrhoea. These are common and may be related to release of inflammatory mediators as a result of reduced relative humidity in the inspired gas. ${ }^{104}$ Humidification of the delivered gas may improve this symptom. ${ }^{104-108}$ Non-heated humidifiers have been used in this regard but refractory patients may benefit from incorporation of a heated humidifier into the PAP circuit. ${ }^{105-108}$ Recent data suggest that elderly patients, individuals who are on medications that may cause mucosal dryness, patients with chronic nasal symptoms, and those who have had a uvulopalatopharyngoplasty are most likely to require a heated humidifier. ${ }^{108}$ In selected patients use of an oronasal mask may increase the relative humidity of the inspired gas, ${ }^{109}$ although one study suggested that this type of interface is less well tolerated than nasal interfaces. ${ }^{110}$ Humidification may reduce the likelihood of epistaxis.

Clinicians may prescribe topical nasal steroids or ipratropium nasal spray to treat nasal complaints associated with PAP therapy. Although we have observed that some patients report improvement following the former treatment, we are unaware of systematic studies evaluating these interventions. Patients who experience oral dryness due to inability to keep the mouth closed during nasal CPAP therapy may derive benefit from a chinstrap or an oronasal mask. ${ }^{111}$

CPAP therapy for OSAHS was initially delivered exclusively via the nasal route. Over the years a number of nasal masks and nasal prong interfaces have evolved and continue to do so in an effort to enhance patient comfort. In addition, some patients have a preference for oronasal masks which do not require exclusively nasal breathing. ${ }^{111} 112$

Adverse consequences of PAP treatment are often related to poorly fitting masks and include skin breakdown and air leaks. ${ }^{113}$ Air leaks at the skin-mask interface or through the mouth when using a nasal interface may preclude achievement of the prescribed pressure and lead to inadequate treatment. If air leaks are directed towards the eyes, conjunctivitis may ensue. Local skin reactions to the interface have also been reported. ${ }^{113}{ }^{114}$ Air leaks may also disrupt sleep. In general, interface-related problems can be resolved for most patients by careful and methodical assessment of all interface options.

Finally, the pressure applied to the upper airway and lungs can result in adverse consequences. Patients may report chest and ear discomfort as well as discomfort associated with exhaling against high pressures. ${ }^{89} 98$ Increased intraocular pressure has also been observed, ${ }^{115}$ as has barotrauma. Although uncommon, barotrauma has been reported in conjunction with PAP therapy, including pneumoencephalus $^{116}$ and pneumothorax. ${ }^{117}$ Clinicians should remain aware of the potential risk of PAP in patients at high risk such as those with bullous lung disease.

\section{MODALITIES OF PAP}

By definition, CPAP reflects delivery of the same magnitude of pressure during both inspiration and expiration. In addition to conventional CPAP, there are other modalities for application of non-invasive PAP.

\section{Bilevel positive airway pressure}

Unlike CPAP which, by definition, provides the same magnitude of pressure during the inspiratory and expiratory portions of the ventilatory cycle, bilevel positive airway pressure (bilevel PAP) permits independent adjustment of the inspiratory and expiratory positive airway pressures (IPAP and EPAP, respectively). The rationale underlying application of this modality is derived from observations that upper airway closure during sleep in OSAHS is an expiratory as well as an inspiratory phase related event. ${ }^{118} 119$ The EPAP level is set to stabilise the upper airway at end expiration such that the airway is sufficiently patent to permit the patient to trigger delivery of IPAP by generating low level inspiratory volume or flow during the subsequent effort. The IPAP level is set to prevent upper airway closure and partial obstruction (hypopnea) during the inspiratory phase of breathing. Since it usually requires less pressure to keep the upper airway adequately patent during expiration than during inspiration, the requisite EPAP is usually lower than the IPAP. ${ }^{120}$ This differs from conventional CPAP in which the pressure delivered during expiration must be as high as that delivered during inspiration. In the "spontaneous mode" of bilevel PAP the patient may breathe with his/her own breathing pattern. Some currently available bilevel PAP devices incorporate the option for the clinician to prescribe a "backup rate" to guarantee a certain number of pressure cycles (or breaths) per minute.

The benefits of bilevel therapy fall largely into two categories: providing ventilatory assistance and improved patient comfort. Resta et al ${ }^{121}$ and Schafer et al ${ }^{122}$ independently found that patients with OSAHS which was refractory to CPAP may be successfully treated with bilevel PAP. Patients who failed on CPAP treatment (persistent apnoea or desaturation) and subsequently had successful alleviation of sleep disordered breathing tended to be more obese with a lower arterial oxygen tension $\left(\mathrm{PaO}_{2}\right)$ and higher arterial carbon dioxide tension $\left(\mathrm{PaCO}_{2}\right)$ during wakefulness. Resta et al $^{121}$ observed that OSAH patients with co-existent chronic obstructive pulmonary disease (COPD) were more likely to require bilevel PAP. The investigators postulated that many patients with COPD find exhaling against positive pressure particularly difficult, such that CPAP may worsen hypercapnia and that lowering the expiratory pressure may enhance 
tolerance. Along these lines, application of bilevel PAP was associated with a lower $\mathrm{PaCO}_{2}$ during sleep than during CPAP administration. Although Schafer et al ${ }^{122}$ observed no association between an obstructive airways disease pattern on spirometry and CPAP failure, those who failed this treatment had significantly higher awake $\mathrm{PaCO}_{2}$ and lower $\mathrm{PaO}_{2}$. After 3 months of bilevel PAP there was a significant increase in awake $\mathrm{PaO}_{2}$ and decrease in $\mathrm{PaCO}_{2}$.

Although anecdotal evidence suggests that bilevel PAP is better tolerated by some patients and may facilitate therapeutic salvage of patients who are intolerant of CPAP or in whom CPAP is inadequately effective, there are no data to support initial treatment of all OSAH patients with bilevel PAP. A prospective trial in which patients with OSAHS were randomised to receive CPAP or bilevel PAP as initial treatment showed that a greater percentage of the study patients who dropped out or were lost to follow up had been assigned to the CPAP treatment arm than the bilevel PAP treatment arm. ${ }^{123}$ However, of the patients who completed the study, adherence was comparable in the two groups.

\section{Pressure ramps and autotitrating PAP}

One approach to addressing complaints of patients who are unable to fall asleep while wearing CPAP is to use a ramp feature. The ramp, available on most commercially available CPAP devices, allows the clinician to set a rate of rise of delivered pressure such that the patient is provided a window of time on less than therapeutic pressure during which s/he has an opportunity to fall asleep. The patient may reset the pressure to a minimal level and reset the ramp at any timefor example, if s/he gets up in the middle of the night and then wishes to return to sleep. The clinician should be cognisant of the possibility that a patient may constantly reset the pressure ramp throughout the night due to pressure intolerance once the target pressure is achieved. This obviously reflects ineffectiveness of the ramp in alleviating patient intolerance. Such "ramp abuse" monitoring the pressure profile and adherence records that are generated by many current CPAP devices and which are downloadable for viewing by the clinician. Surprisingly, there have been no published trials evaluating the effectiveness of pressure ramps in improving acceptance and adherence to CPAP.

Autotitrating CPAP (A-CPAP) has recently been introduced in an attempt to minimise the average overnight pressure requirements of patients with OSAHS. These systems are designed to modulate the delivered PAP in response to changes in upper airway resistance which may be associated with varying conditions over the night, including changing sleep stage and body position. Although the specific algorithms are proprietary and differ between manufacturers, these devices are, in general, designed to detect impending upper airway collapse and respond by increasing the delivered pressure. ${ }^{125-135}$ After a defined period of upper airway stability, the pressure is gradually reduced until instability is once again identified. Thus, unlike fixed pressure CPAP (F-CPAP) which must remain throughout the night at a sufficiently high level to maintain upper airway patency under the most unstable conditions, A-CPAP levels float to accommodate the physiological requirements to maintain upper airway patency. The average overnight pressure required during A-CPAP application is usually the same or lower in autotitrating systems than in conventional F-CPAP. ${ }^{127-129}$ The putative advantages of A-CPAP include improved patient comfort and adherence to treatment compared with F-CPAP. ${ }^{130-132}$

The effectiveness of A-CPAP in reducing AHI and the arousal index is similar to $\mathrm{F}-\mathrm{CPAP},{ }^{133}$ as is amelioration of symptoms. ${ }^{129}$ Data regarding the benefits conferred by
A-CPAP regarding acceptance and adherence are mixed, however, with some studies suggesting improvement on A-CPAP and others finding no difference compared with F-CPAP. ${ }^{128}{ }^{131}$

Another potentially useful application of A-CPAP is as a tool to enhance the efficiency of pressure titration in the sleep laboratory. In such an application, A-CPAP is employed to determine an F-CPAP prescription for home use. In this regard, a fixed pressure prescription identified from an overnight laboratory trial of A-CPAP (the fixed pressure prescription is defined as that pressure at or below which the patient received for $90 \%$ or $95 \%$ of the overnight trial period) has been found to approximate pressure prescription derived from manual CPAP titration. ${ }^{133}{ }^{134}$ When used in this manner, A-CPAP relieves the sleep technician of the obligation of manually performing the titration. Theoretically, this provides a greater opportunity to address patient comfort and optimise patient education. The use of A-CPAP, applied in an unattended setting to established a long term F-CPAP pressure prescription, has not been adequately studied and its use for that purpose is not currently recommended. ${ }^{135} 136$

Unresolved problems with A-CPAP include inappropriate pressure adjustments during interface or mouth leaks which impair the algorithms from effectively detecting upper airway instability ${ }^{134}$ In addition, A-CPAP has been evaluated only in selected populations with limited or no available data addressing its efficacy or effectiveness in patients with underlying cardiopulmonary disorders, central sleep apnoea, CSB, obesity-hypoventilation, neurological or chest wall abnormalities. Until such data become available, A-CPAP should probably not be used in these patients. ${ }^{135}{ }^{136}$ Also, patients with OSAHS who do not snore, as might occur following unsuccessful uvulopalatopharyngoplasty, should not use A-CPAP devices with algorithms that use pressure or airflow vibrations in the algorithm to modulate adjustment of delivered pressure. ${ }^{136}$

\section{CONCLUSIONS}

CPAP is very effective in treating symptoms associated with OSAHS. There are few serious risks and these occur relatively uncommonly. This treatment is generally well tolerated, particularly in view of its intrusive nature. Nonetheless, therapeutic acceptance and adherence remain significant challenges to patients and clinicians. Management of patients who are intolerant of CPAP requires that the clinician identifies the specific source(s) of the intolerance. Problems related to the interface or route of administration demand exploration of mask or nasal prong options. Difficulties related to nasal or pharyngeal discomfort may be addressed by incorporating a non-heated or heated humidifier into the positive pressure circuit or prescribing judicious use of topical nasal steroids. For those patients who do not tolerate CPAP because of discomfort associated with the requisite therapeutic pressure, or those who have waking hypoxaemia or hypercapnia and who may benefit from ventilatory assistance as well as upper airway stabilisation, bilevel PAP may be an acceptable alternative. A-CPAP may also be an option for OSAHS patients who, when awake, are unable to tolerate administration of the therapeutic pressure required during sleep with consequent impairment of the ability to initiate sleep. The advent of PAP for treatment of patients with OSAHS represents an obvious improvement over the treatment of choice which it replaced over two decades ago, tracheostomy. Although PAP remains an imperfect intervention, it has continued to evolve and improve such that patients who would not have been able to use this therapy even in the recent past can benefit from it today. 


\section{Authors' affiliations}

P Gordon, Critical Care and Sleep Medicine, University of Pittsburgh School of Medicine, Pittsburgh, PA, USA

M H Sanders, Division of Pulmonary, Allergy \& Critical Care Medicine, Department of Medicine, University of Pittsburgh School of Medicine, Pittsburgh, PA, USA

M H Sanders is a consultant to Respironics Inc and has a financial interest in BiPAP ${ }^{\circledR}$ and $\mathrm{CFlex}^{\circledR}$.

Supported in part by NIH Training Grant 2-T32-HL07563.

\section{REFERENCES}

1 Young T, Palta M, Dempsey J, et al. The occurrence of sleep-disordered breathing among middle-aged adults. N Engl I Med 1993;328:1230-5

2 Newman AB, Nieto FJ, Guidry U, et al. Relation of sleep-disordered breathing to cardiovascular disease risk factors: the Sleep Heart Health Study. Am J Epidemiol 2001;154:50-9.

3 Nieto FJ, Young TB, Lind BK, et al. Association of sleep-disordered breathing, sleep apnea, and hypertension in a large community-based study. Sleep Heart Health Study. JAMA 2000;283:1829-36.

4 Peppard PE, Young T, Palta M, et al. Prospective study of the association between sleep-disordered breathing and hypertension. N Engl J Med 2000;342:1378-84.

5 Young T, Peppard P. Sleep-disordered breathing and cardiovascular disease: epidemiologic evidence for a relationship. Sleep 2000;23(Suppl 4):S122-6.

6 Barbe, Pericas J, Munoz A, et al. Automobile accidents in patients with sleep apnea syndrome. An epidemiological and mechanistic study. Am J Respir Crit Care Med 1998;158:18-22.

7 Findley $\amalg$, Suratt PM. Serious motor vehicle crashes: the cost of untreated sleep apnoea. Thorax 2001;56:505.

8 Teran-Santos J, Jimenez-Gomez A, Cordero-Guevara J. The association between sleep apnea and the risk of traffic accidents. Cooperative Group Burgos-Santander. N Engl J Med 1999;340:847-51

9 Young T, Blustein J, Finn L, et al. Sleep-disordered breathing and motor vehicle accidents in a population-based sample of employed adults. Sleep 1997;20:608-13.

10 Sullivan CE, Issa FG, Berthon-Jones $M$, et al. Reversal of obstructive sleep apnoea by continuous positive airway pressure applied through the nares. Lancet 1981;1:862-5.

11 Alex CG, Aronson RM, Onal E, et al. Effects of continuous positive airway pressure on upper airway and respiratory muscle activity. $J$ Appl Physiol 1987;62:2026-30.

12 Hoffstein V, Zamel N, Phillipson EA. Lung volume dependence of pharyngeal cross-sectional area in patients with obstructive sleep apnea. Am Rev Respir Dis 1984; 130:175-8.

13 Bradley TD, Brown IG, Grossman RF, et al. Pharyngeal size in snorers, nonsnorers, and patients with obstructive sleep apnea. N Engl J Med 1986; $315: 1327-31$

14 Series $F$, Cormier $Y$, Desmeules M. Influence of passive changes of lung volume on upper airways. J Appl Physiol 1990;68:2159-64.

15 Begle RL, Badr S, Skatrud JB, et al. Effect of lung inflation on pulmonary resistance during NREM sleep. Am Rev Respir Dis 1990;141:854-60.

16 Brown IG, McClean PA, Webster PM, et al. Lung volume dependence of esophageal pressure in the neck. J Appl Physiol 1985;59:1849-54.

17 Van de Graaff WB. Thoracic influence on upper airway patency. J Appl Physiol 1988;65:2124-31.

18 Van de Graaff WB. Thoracic traction on the trachea: mechanisms and magnitude. J Appl Physiol 1991;70:1328-36.

19 Tuck SA, Remmers JE. Mechanical properties of the passive pharynx in Vietnamese pot-bellied pigs. II. Dynamics. J Appl Physiol 2002;92:2236-44

20 Tuck SA, Remmers JE. Mechanical properties of the passive pharynx in Vietnamese pot-bellied pigs. I. Statics. J Appl Physiol 2002;92:2229-35.

21 Strohl K, Redline S. Nasal CPAP therapy, upper airway muscle activation, and obstructive sleep apnea. Am Rev Respir Dis 1986;134:555-8.

22 Rapoport D, Garay S, Goldring R. Nasal CPAP in obstructive sleep apnea; mechanisms of action. Bull Eur Physiopathol Respir 1983;19:616-20.

23 Series F, Cormier Y, Couture J, et al. Changes in upper airway resistance with lung inflation and positive airway pressure. J Appl Physiol 1990:68:1075-9.

24 Abbey NC, Cooper KR, Kwentus JA. Benefit of nasal CPAP in obstructive sleep apnea is due to positive pharyngeal pressure. Sleep 1989;12:420-2

25 Loube DI, Gay PC, Strohl KP, et al. Indications for positive airway pressure treatment of adult obstructive sleep apnea patients: a consensus statement. Chest 1999;115:863-6.

26 Anon. Practice parameters for treatment of OSA in adults. Sleep 1997;20:406-22.

27 Medicare. Medicare guidelines. http://www.hcfa.gov/pubforms/06_cim/ ci60.htm \# 60_17, 2001.

28 Barbe F, Mayoralas LR, Duran J, et al. Treatment with continuous positive airway pressure is not effective in patients with sleep apnea but no daytime sleepiness. a randomized, controlled trial. Ann Intern Med 2001:134:1015-23.

29 Engleman HM, Cheshire KE, Deary IJ, et al. Daytime sleepiness, cognitive performance and mood after continuous positive airway pressure for the sleep apnoea/hypopnoea syndrome. Thorax 1993;48:911-4.
30 Engleman HM, Martin SE, Deary IJ, et al. Effect of continuous positive airway pressure treatment on daytime function in sleep apnoea/hypopnoed syndrome. Lancet 1994;343:572-5.

31 Engleman HM, Martin SE, Kingshott RN, et al. Randomised placebo controlled trial of daytime function after continuous positive airway pressure (CPAP) therapy for the sleep apnoea/hypopnoea syndrome. Thorax 1998;53:341-5

32 Munoz A, Mayoralas LR, Barbe F, et al. Long-term effects of CPAP on daytime functioning in patients with sleep apnoea syndrome. Eur Respir J 2000;15:676-81.

33 Derderian SS, Bridenbaugh RH, Rajagopal KR. Neuropsychologic symptoms in obstructive sleep apnea improve after treatment with nasal continuous positive airway pressure. Chest 1988:94:1023-7.

34 Lamphere J, Roehrs T, Wittig R, et al. Recovery of alertness after CPAP in apnea. Chest 1989;96:1364-7

35 Monasterio C, Vidal S, Duran J, et al. Effectiveness of continuous positive airway pressure in mild sleep apnea-hypopnea syndrome, Am J Respir Crit Care Med $2001 ; 164: 939-43$.

36 Ballester E, Badia JR, Hernandez L, et al. Evidence of the effectiveness of continuous positive airway pressure in the treatment of sleep apnea/ hypopnea syndrome. Am J Respir Crit Care Med 1999;159:495-501.

37 Engleman HM, Kingshott RN, Wraith PK, et al. Randomized placebocontrolled crossover trial of continuous positive airway pressure for mild sleep apnea/hypopnea syndrome. Am J Respir Crit Care Med 1999:159:461-7.

38 Stradling JR, Davies RJ. Is more NCPAP better? Sleep 2000;23(Suppl 4):S150-3.

39 Jenkinson C, Davies RJ, Mullins R, et al. Comparison of therapeutic and subtherapeutic nasal continuous positive airway pressure for obstructive sleep apnoea: a randomised prospective paralle trial. Lancet 1999;353:2100-5

40 Montserrat JM, Ferrer M, Hernandez L, et al. Effectiveness of CPAP treatment in daytime function in sleep apnea syndrome: a randomized controlled study with an optimized placebo. Am J Respir Crit Care Med 2001;164:608-13.

41 Kribbs NB, Pack Al, Kline LR, et al. Effects of one night without nasal CPAP treatment on sleep and sleepiness in patients with obstructive sleep apnea. Am Rev Respir Dis 1993;147:1162-8.

42 Naegele B, Thouvard V, Pepin J, et al. Deficits of cognitive executive functions in patients with sleep apnea syndrome. Sleep 1995;18:43-52.

43 Engleman HM, Kingshott RN, Martin SE, et al. Cognitive function in the sleep apnea/hypopnea syndrome (SAHS). Sleep 2000;23(Suppl 4):S102-8.

44 Cheshire K, Engleman H, Deary l, et al. Factors impairing daytime performance in patients with sleep apnea/hypopnea syndrome. Arch Intern Med 1992;152:538-41.

45 Engleman HM, Asgari-Jirhandeh N, McLeod AL, et al. Self-reported use of CPAP and benefits of CPAP therapy: a patient survey. Chest 1996;109:1470-6

46 Hack M, Davies RJ, Mullins R, et al. Randomised prospective parallel trial of therapeutic versus subtherapeutic nasal continuous positive airway pressure on simulated steering performance in patients with obstructive sleep apnoea. Thorax 2000;55:224-31.

47 George CF. Reduction in motor vehicle collisions following treatment of sleep apnoea with nasal CPAP. Thorax 2001;56:508-12.

48 Nieto FJ, Young TB, Lind BK, et al. Association of sleep-disordered breathing, sleep apnea, and hypertension in a large community-based study. Sleep Heart Health Study. JAMA 2000;283:1829-36.

49 Hla KM, Young TB, Bidwell T, et al. Sleep apnea and hypertension. A population-based study. Ann Intern Med 1994;120:382-8.

50 Young T, Peppard P, Palta $M$, et al. Population-based study of sleepdisordered breathing as a risk factor for hypertension. Arch Intern Med 1997; 157:1746-52.

51 Kiselak J, Clark M, Pera V, et al. The association between hypertension and sleep apnea in obese patients. Chest 1993;104:775-80.

52 Lavie $\mathbf{P}$, Herer $\mathrm{P}$, Hoffstein $\mathrm{V}$. Obstructive sleep apnoea syndrome as a risk factor for hypertension: population study. BMJ 2000;320:479-82.

53 Dimsdale JE, Loredo JS, Profant J. Effect of continuous positive airway pressure on blood pressure: a placebo trial. Hypertension 2000;35:144-7.

54 Faccenda JF, Mackay TW, Boon NA, et al. Randomized placebo-controlled trial of continuous positive airway pressure on blood pressure in the sleep apnea-hypopnea syndrome. Am J Respir Crit Care Med 2001;163:344-8.

55 Pepperell JC, Ramdassingh-Dow S, Crosthwaite N, et al. Ambulatory blood pressure after therapeutic and subtherapeutic nasal continuous positive airway pressure for obstructive sleep apnoea: A randomised parallel trial. Lancet 2002:359:204-10.

56 Wilcox I, Grunstein RR, Hedner JA, et al. Effect of nasal continuous positive airway pressure during sleep on 24-hour blood pressure in obstructive sleep apnea. Sleep 1993;16:539-44.

57 Suzuki M, Otsuka K, Guilleminault C. Long-term nasal continuous positive airway pressure administration can normalize hypertension in obstructive sleep apnea patients. Sleep 1993;16:545-9.

58 Mayer J, Becker $\mathrm{H}$, Brandenburg U, et al. Blood pressure and sleep apnea: results of long-term nasal continuous positive airway pressure therapy. Cardiology 1991;79:84-92.

59 MacMahon S, Peto R, Cutler J, et al. Blood pressure, stroke, and coronary heart disease. Part 1, Prolonged differences in blood pressure: prospective observational studies corrected for the regression dilution bias. Lancet 1990;335:765-74

60 Javaheri S. Central sleep apnea-hypopnea syndrome in heart failure: prevalence, impact, and treatment. Sleep 1996;19:S229-31. 
61 Malone S, Liu P, Holloway R, et al. Obstructive sleep apnoea in patients with dilated cardiomyopathy: effects of continuous positive airway pressure. Lancet 1991;338:1480-4.

62 Bradley TD, Floras JS. Pathophysiologic and therapeutic implications of sleep apnea in congestive heart failure. J Card Fail 1996:2:223-40.

63 Midelton GT, Frishman WH, Passo SS. Congestive heart failure and continuous positive airway pressure therapy: support of a new modality for improving the prognosis and survival of patients with advanced congestive heart failure. Heart Dis 2002;4:102-9.

64 Bradley TD, Holloway RM, McLaughlin PR, et al. Cardiac output response to continuous positive airway pressure in congestive heart failure. Am Rev Respir Dis 1992;145:377-82.

65 Garpestad E, Katayama H, Parker JA, et al. Stroke volume and cardiac output decrease at termination of obstructive apneas. J Appl Physiol 1992;73:1743-8.

66 Davies RJ, Harrington KJ, Ormerod OJ, et al. Nasal continuous positive airway pressure in chronic heart failure with sleep-disordered breathing. Am Rev Respir Dis 1993;147:630-4.

67 Sin DD, Logan AG, Fitzgerald FS, et al. Effects of continuous positive airway pressure on cardiovascular outcomes in heart failure patients with and without Cheyne-Stokes respiration. Circulation 2000;102:61-6.

68 Nelesen RA, Yu H, Ziegler MG, et al. Continuous positive airway pressure normalizes cardiac autonomic and hemodynamic responses to a laboratory stressor in apneic patients. Chest 2001;119:1092-101.

69 Naughton MT, Bradley TD. Sleep apnea in congestive heart failure. Clin Chest Med 1998;19:99-113.

70 Krieger J, Grucker D, Sforza E, et al. Left ventricular ejection fraction in obstructive sleep apnea. Effects of long-term treatment with nasal continuous positive airway pressure. Chest 1991;100:917-21.

71 Krieger J, Follenius $M$, Sforza $E$, et al. Effects of treatment with nasal continuous positive airway pressure on atrial natriuretic peptide and arginine vasopressin release during sleep in patients with obstructive sleep apnoea. Clin Sci (Lond) 1991;80:443-9.

72 Krachman SL, D'Alonzo GE, Berger TJ, et al. Comparison of oxygen therapy with nasal continuous positive airway pressure on Cheyne-Stokes respiration during sleep in congestive heart failure. Chest 1999;116:1550-7.

73 Phillips BG, Somers VK. Neural and humoral mechanisms mediating cardiovascular responses to obstructive sleep apnea. Respir Physiol 2000;1 19:181-7.

74 Somers VK, Dyken ME, Clary MP, et al. Sympathetic neural mechanisms in obstructive sleep apnea. J Clin Invest 1995;96:1897-904.

75 Narkiewicz K, van de Borne PJ, Montano N, et al. Contribution of tonic chemoreflex activation to sympathetic activity and blood pressure in patients with obstructive sleep apnea. Circulation 1998;97:943-5.

76 Fletcher EC. Effect of episodic hypoxia on sympathetic activity and blood pressure. Respir Physiol 2000;1 19:189-97.

77 Narkiewicz K, Kato M, Philips B, et al. Nocturnal continuous positive airway pressure decreases daytime sympathetic traffic in obstructive sleep apnea. Circulation 1999; 100:2332-5

78 Waradekar NV, Sinoway LI, Zwillich CW, et al. Influence of treatment on muscle sympathetic nerve activity in sleep apnea. Am J Respir Crit Care Med 1996; 153:1333-8.

79 Dean RT, Wilcox I. Possible atherogenic effects of hypoxia during obstructive sleep apnea. Sleep 1993;16:S15-21; discussion S21-2.

80 Chin K, Nakamura T, Shimizu K, et al. Effects of nasal continuous positive airway pressure on soluble cell adhesion molecules in patients with obstructive sleep apnea syndrome. Am J Med 2000;109:562-7.

81 Duchna HW, Guilleminault C, Stoohs RA, et al. Vascular reactivity in obstructive sleep apnea syndrome. Am J Respir Crit Care Med 2000;161:187-91.

82 Phillips BG, Kato M, Narkiewicz K, et al. Increases in leptin levels, sympathetic drive, and weight gain in obstructive sleep apnea. Am J Physiol Heart Circ Physiol 2000;279:H234-7.

83 Haynes WG, Morgan DA, Walsh SA, et al. Receptor-mediated regional sympathetic nerve activation by leptin. J Clin Invest 1997; 100:270-8.

84 Nonogaki K. Obesity: autonomic circuits versus feeding. Nat Med 1999;5:742-3

85 Chin K, Shimizu K, Nakamura T, et al. Changes in intra-abdominal visceral fat and serum leptin levels in patients with obstructive sleep apnea syndrome following nasal continuous positive airway pressure therapy. Circulation 1999; 100:706-12.

86 Fleury B, Rakotonanahary D, Tehindrazanarivelo AD, et al. Long-term compliance to continuous positive airway pressure therapy (nCPAP) set up during a split-night polysomnography. Sleep 1994:17:512-5.

87 Strollo PJ Jr, Sanders MH, Costantino JP, et al. Split-night studies for the diagnosis and treatment of sleep-disordered breathing. Sleep 1996; 19:S255-9.

88 Rauscher H, Popp W, Wanke T, et al. Acceptance of CPAP therapy for sleep apnea. Chest 1991;100:1019-23.

89 Hoffstein V, Viner S, Mateika S, et al. Treatment of obstructive sleep apnea with nasal continuous positive airway pressure. Patient compliance, perception of benefits, and side effects. Am Rev Respir Dis 1992;145:841-5.

90 Reeves-Hoché MK, Meck R, Zwillich CW. Nasal CPAP: an objective evaluation of patient compliance. Am J Respir Crit Care Med 1994; 149:149-54.

91 Meurice JC, Dore P, Paquereau J, et al. Predictive factors of long-term compliance with nasal continuous positive airway pressure treatment in sleep apnea syndrome. Chest 1994;105:429-33.

92 Kribbs NB, Pack Al, Kline LR, et al. Objective measurement of patterns of nasal CPAP use by patients with obstructive sleep apnea. Am Rev Respir Dis 1993; 147:887-95.
93 Engleman HM, Martin SE, Douglas NJ. Compliance with CPAP therapy in patients with the sleep apnoea/hypopnoea syndrome. Thorax 1994,49:263-6.

94 Weaver TE, Kribbs NB, Pack Al, et al. Night-to-night variability in CPAP use over the first three months of treatment. Sleep 1997;20:278-83.

95 McArdle N, Devereux G, Heidarnejad H, et al. Long-term use of CPAP therapy for sleep apnea/hypopnea syndrome. Am J Respir Crit Care Med 1999; 159:1108-14.

96 Engleman HM, Martin SE, Deary IJ, et al. Effect of CPAP therapy on daytime function in patients with mild sleep apnoea/hypopnoea syndrome. Thorax 1997;52:114-9

97 Alarcon A, Leon C, Maimo A, et al. Compliance with nasal continuous positive airway pressure (CPAP) treatment in sleep apnea-hypopnea syndrome. Arch Bronconeumol 1995:31:56-61.

98 Waldhorn RE, Herrick TW, Nguyen MC, et al. Long-term compliance with nasal continuous positive airway pressure therapy of obstructive sleep apnea. Chest 1990;97:33-8.

99 Tashkin DP, Rand C, Nides M, et al. A nebulizer chronolog to monitor compliance with inhaler use. Am J Med 1991;91:33-36S.

100 Mawhinney H, Spector SL, Kinsman RA, et al. Compliance in clinical trials of two nonbronchodilator, antiasthma medications. Ann Allergy 1991;66:294-9.

101 Hoy CJ, Vennelle M, Kingshott RN, et al. Can intensive support improve continuous positive airway pressure use in patients with the sleep apnea/ hypopnea syndrome? Am J Respir Crit Care Med 1999;159:1096-100.

102 Hui DS, Chan JK, Choy DK, et al. Effects of augmented continuous positive airway pressure education and support on compliance and outcome in a Chinese population. Chest 2000;117:1410-6.

103 Fletcher EC, Luckett RA. The effect of positive reinforcement on hourly compliance in nasal continuous positive airway pressure users with obstructive sleep apnea. Am Rev Respir Dis 1991;143:936-41.

104 Richards GN, Cistulli PA, Ungar RG, et al. Mouth leak with nasal continuous positive airway pressure increases nasal airway resistance. Am J Respir Crit Care Med 1996;154:182-6.

105 Massie CA, Hart RW, Peralez K, et al. Effects of humidification on nasal symptoms and compliance in sleep apnea patients using continuous positive airway pressure. Chest 1999:116:403-8.

106 Wiest GH, Lehnert G, Bruck WM, et al. A heated humidifier reduces upper airway dryness during continuous positive airway pressure therapy. Respir Med 1999;93:21-6.

107 Winck JC, Delgado JL, Almeida JM, et al. Heated humidification during nasal continuous positive airway pressure for obstructive sleep apnea syndrome: objective evaluation of efficacy with nasal peak inspiratory flow measurements. Am J Rhinol 2002;16:175-7.

108 Rakotonanahary D, Pelletier-Fleury N, Gagnadoux F, et al. Predictive factors for the need for additional humidification during nasal continuous positive airway pressure therapy. Chest 2001;119:460-5.

109 Martins De Araujo MT, Vieira SB, Vasquez EC, et al. Heated humidification or face mask to prevent upper airway dryness during continuous positive airway pressure therapy. Chest 2000;117:142-7.

110 Mortimore IL, Whittle AT, Douglas NJ. Comparison of nose and face mask CPAP therapy for sleep apnoea. Thorax 1998;53:290-2.

111 Sanders MH, Kern NB, Stiller RA, et al. CPAP therapy via oronasal mask for obstructive sleep apnea. Chest 1994;106:774-9.

112 Prosise GL, Berry RB. Oral-nasal continuous positive airway pressure as a treatment for obstructive sleep apnea. Chest 1994;106:180-6.

113 Pepin JL, Leger $P$, Veale D, et al. Side effects of nasal continuous positive airway pressure in sleep apnea syndrome. Study of 193 patients in two French sleep centers. Chest 1995; 107:375-81.

114 Nino-Murcia G, McCann CC, Bliwise DL, et al. Compliance and side effects in sleep apnea patients treated with nasal continuous positive airway pressure. West J Med 1989;150:165-9.

115 Alvarez-Sala R, Diaz S, Prados C, et al. Increase of intraocular pressure during nasal CPAP. Chest 1992;101:1477.

116 Jarjour NN, Wilson P. Pneumocephalus associated with nasal continuous positive airway pressure in a patient with sleep apnea syndrome. Chest 1989;96:1425-6.

117 Herrejon Silvestre A, Inchaurraga Alvarez I, Marin Gonzalez M. Spontaneous pneumothorax associated with the use of nighttime BiPAP with a nasal mask. Arch Bronconeumol 1998;34:512.

118 Sanders MH, Moore SE. Inspiratory and expiratory partitioning of airway resistance during sleep in patients with sleep apnea. Am Rev Respir Dis 1983; 127:554-8.

119 Sanders MH, Rogers RM, Pennock BE. Prolonged expiratory phase in sleep apnea. A unifying hypothesis. Am Rev Respir Dis 1985;131:401-8

120 Sanders MH, Kern N. Obstructive sleep apnea treated by independently adjusted inspiratory and expiratory positive airway pressures via nasal mask. Physiologic and clinical implications. Chest 1990;98:317-24.

121 Resta O, Guido P, Picca V, et al. Prescription of nCPAP and nBIPAP in obstructive sleep apnoea syndrome: Italian experience in 105 subjects. A prospective two centre study. Respir Med 1998;92:820-7.

122 Schafer H, Ewig S, Hasper E, et al. Failure of CPAP therapy in obstructive sleep apnoea syndrome: predictive factors and treatment with bilevelpositive airway pressure. Respir Med 1998;92:208-15.

123 Reeves-Hochè $M$, Hudgel $D$, Meck R, et al. Continuous versus bilevel positive airway pressure for obstructive sleep apnea. Am J Respir Crit Care Med 1995; 151:443-9.

124 Pressman MR, Peterson DD, Meyer TJ, et al. Ramp abuse. A novel form of patient noncompliance to administration of nasal continuous positive airway pressure for treatment of obstructive sleep apnea. Am J Respir Crit Care Med 1995; 151:1632-4. 
125 Lofaso $F$, Lorino AM, Duizabo $D$, et al. Evaluation of an auto-nCPAP device based on snoring detection. Eur Respir J 1996;9:1795-800.

126 Randerath WJ, Parys K, Feldmeyer F, et al. Self-adjusting nasal continuous positive airway pressure therapy based on measurement of impedance: a comparison of two different maximum pressure levels. Chest 1999:116:991-9.

127 Farre R, Peslin R, Montserrat JM, et al. Flow-dependent positive airway pressure to maintain airway patency in sleep apnea-hypopnea syndrome. Am J Respir Crit Care Med 1998;157:1855-63.

128 Teschler $\mathrm{H}$, Wessendorf TE, Farhat AA, et al. Two months auto-adjusting versus conventional nCPAP for obstructive sleep apnoea syndrome. Eur Respir J 2000;15:990-5

129 Hudgel DW, Fung C. A long-term randomized, cross-over comparison of auto-titrating and standard nasal continuous airway pressure. Sleep 2000;23:645-8.

130 Berthon-Jones $M$. Feasibility of a self-setting CPAP machine. Sleep 1993;16:S120-1.

131 Meurice JC, Marc I, Series F. Efficacy of auto-CPAP in the treatment of obstructive sleep apnea/hypopnea syndrome. Am J Respir Crit Care Med 1996;153:794-8.
132 Konermann M Sanner BM, Vyleta M, et al. Use of conventional and selfadjusting nasal continuous positive airway pressure for treatment of severe obstructive sleep apnea syndrome: a comparative study. Chest 1998; 113:714-8.

133 Teschler $\mathrm{H}$, Farhat AA, Exner $\mathrm{V}$, et al. AutoSet nasal CPAP titration: constancy of pressure, compliance and effectiveness at 8 month follow-up. Eur Respir J 1997; 10:2073-8.

134 Teschler $\mathrm{H}$, Berthon-Jones $M$, Thompson $A B$, et al. Automated continuous positive airway pressure titration for obstructive sleep apnea syndrome. Am J Respir Crit Care Med 1996;154:734-40.

135 Berry RB, Parish JM, Hartse KM. The use of auto-titrating continuous positive airway pressure for treatment of adult obstructive sleep apnea. An American Academy of Sleep Medicine Review. Sleep 2002;25:148-73.

136 Littner M, Hirshkowitz M, Davila D, et al. Practice parameters for the use of auto-titrating continuous positive airway pressure devices for titrating pressures and treating adult patients with obstructive sleep apnea syndrome. An American Academy of Sleep Medicine report. Sleep 2002;25:143-7.

\section{LUNG ALERT}

\section{Endothelial dysfunction in sleep-disordered breathing seems to be more severe in women}

$\Delta$ Faulx MD, Larkin EK, Hoit BD, et al. Sex influences endothelial function in sleep-disordered breathing. Sleep 2004;27:1113-20

S leep disordered breathing (SDB) is associated with an increased prevalence of hypertension and cardiovascular disease independent of age, sex, and body mass index. The adverse cardiovascular effects are thought to be due to combinations of overnight hypoxaemia, hypercapnia, and sympathetic nervous system overactivity. There is limited research that has addressed the influence of these variable overnight physiological changes on the endothelial function. Brachial artery ultrasonography is a reliable noninvasive surrogate marker of endothelial function which allows repetitive dynamic assessment of both arterial diameter and velocity. Reduced flow mediated dilation (FMD) of the brachial artery in response to increased stress correlates with angiographically proven coronary artery disease. The percentage increase in peak blood flow (PBF) in response to transient arterial occlusion and hypoxia has also been reported as a measure of resistance vessel endothelial function.

Families affected with SDB were identified and neighbourhood control families were also recruited. Of the 2462 members, 700 underwent in-depth studies of cardiovascular and metabolic risk factors and 193 participants aged 16 years and older were studied. Individuals with known cardiovascular disease or diabetes were excluded. Participants underwent overnight polysomnography and brachial artery ultrasonography the following morning.

The authors concluded that increasing severity of SDB is associated with decreasing FMD and PBF. However, these relationships were observed only in women. This was unexpected but previous studies have suggested that there may be gender differences in endothelial function. This suggests that women with SDB may be more vulnerable to early SDB related cardiovascular disease than men with relatively mild levels of SDB, but we do not yet know what mechanisms are involved in this difference.

P Bhatia Specialist Registrar, Respiratory/GIM, North Manchester General Hospital, Manchester, UK 